\title{
Noninvasive Surrogates for Left Ventricular Filling Pressure in Patients with Valvular Heart Disease
}

\author{
Debora Brala1,2, Thomas G. Allison³, Wilhelm Haverkamp1, Ingolf Schimke, Olaf Schulz1,4* \\ ${ }^{1}$ Department of Cardiology, Universitätsmedizin Berlin, Berlin, Germany \\ ${ }^{2}$ Department of Cardiology, Sana Klinikum Lichtenberg, Berlin, Germany \\ ${ }^{3}$ Deparment of Cardiovascular Diseases, Mayo Clinic and Medical School, Rochester, MN, USA \\ ${ }^{4}$ Kardio-West, Praxis für Interventionelle und Konventionelle Kardiologie Spandau, Berlin, Germany \\ Email: ${ }^{*}$ oschulz@kardio-west.de
}

Received 4 March 2015; accepted 19 March 2015; published 25 March 2015

Copyright (C) 2015 by authors and Scientific Research Publishing Inc.

This work is licensed under the Creative Commons Attribution International License (CC BY).

http://creativecommons.org/licenses/by/4.0/

c) (i) Open Access

\section{Abstract}

Background: Invasive measurement of left ventricular filling pressure is the gold standard for determining diastolic dysfunction and predicting subsequent outcomes. For repetitive assessment of diastolic function during long-term management, noninvasive surrogates are used. Their reliability and reproducibility should be validated separately for different cardiovascular diseases and conditions. The aim of this study was to identify noninvasive surrogates of invasively derived left ventricular filling pressure and to relate these surrogates to outcomes (death or valve replacement) in patients with stable, asymptomatic valvular heart disease and preserved ejection fraction. Materials and Methods: In a first cohort, we investigated 54 patients who had spiroergometry, echocardiography, and left heart catheterization within a range of 100 days. In a second cohort ( $\mathrm{n}=$ 64), noninvasive measures were related to outcomes after follow-up of $694 \pm 576$ days. Transmitral doppler $E$ /tissue doppler $E^{\prime}\left(E / E^{\prime}\right), E$ /flow propagation velocity $(E / V p)$, isovolumetric relaxation time/time to $E^{\prime}$-time to $\mathrm{E}$ (IVRT/TE'-TE), ventilatory efficiency (VE/ $\mathrm{VCO}_{2}$ slope), $\mathrm{O}_{2}$ consumption at anaerobic threshold and at peak exercise $\left(\mathrm{VO}_{2} \mathrm{AT}, \mathrm{VO}_{2}\right.$ peak) as well as NT-pro brain natriuretic peptide (NTpro-BNP) were assessed in relation to left ventricular filling pressure and outcome. Results: NT-proBNP, $\mathrm{VO}_{2} \mathrm{AT}, \mathrm{VE} / \mathrm{VCO}_{2}$ slope as well as echocardiographic surrogates $\mathrm{E} / \mathrm{E}^{\prime}$ and $\mathrm{E} /$ flow propagation velocity were indicators of elevated end diastolic filling pressure. In multivariable analysis, $\mathrm{VO}_{2} \mathrm{AT}$ was the only independent predictor. NT-proBNP was the only surrogate of left ventricular filling pressure which predicted outcome. Conclusion: In patients with asymptomatic valvular heart disease and preserved systolic function, spiroergometric parameters and NT-proBNP performed best to assess filling pressure. Only NT-proBNP showed prognostic value in this cohort.

\footnotetext{
*Corresponding author.
}

How to cite this paper: Brala, D., Allison, T.G., Haverkamp, W., Schimke, I. and Schulz, O. (2015) Noninvasive Surrogates for Left Ventricular Filling Pressure in Patients with Valvular Heart Disease. International Journal of Clinical Medicine, 6, 193203. http://dx.doi.org/10.4236/ijcm.2015.63025 


\section{Keywords}

\section{Filling Pressure, NT-proBNP, E/E', $\mathrm{VO}_{2}, \mathrm{VE} / \mathrm{VCO}_{2}$ slope, Valvular Heart Disease}

\section{Introduction}

Patients with diastolic dysfunction [1] as well as heart failure with preserved ejection fraction (EF) have a poor outcome [2]. Left ventricular filling pressure has been identified as the best index of diastolic function and subsequent mortality [3].

While invasively measured left ventricular end diastolic pressure (LVEDP) is the gold standard for evaluating filling pressures, management of chronic patients is better served by noninvasive measurements which are reproducible and reliably correlate with invasive findings. Several echocardiographic parameters have been introduced as surrogates for left ventricular filling pressure. However, performance of these surrogate markers varied substantially according to the characteristics of a given cohort [4]-[7]. LVEDP itself is depending on the type and stage of the valvular disease and is co-influenced by factors like fluid state or medication at the time of measurement. Recent recommendations for echocardiographic assessment using a comprehensive approach with multiple parameters [8] are complex and require extensive analysis. The reliability of these parameters has to be validated separately in different cohorts in order to identify the most applicable ones.

To focus on which parameters are most applicable, their reliability in different cohorts has to be validated separately. Filling pressure is influencing the prognosis of patients with asymptomatic valvular heart disease (VHD) and preserved EF [9], and by this, may also be important for optimal timing of valve surgery. Therefore, in patients with asymptomatic VHD and preserved EF, we validate that non-invasive surrogates of filling pressure derive from echocardiography, spiroergometry, and laboratory biomarkers by their association with invasively measured LVEDP as well as their predictive value for outcomes.

\section{Material and Methods}

\subsection{Patients}

We retrospectively recruited, consecutively, two patient cohorts from a study of exercise tolerance in patients with VHD. It lasted from July 2004 until December 2011; follow-up was terminated in August 2012. For the issue of the presented manuscript, all patients who had baseline parameters that were important for the analysis of LVEDP surrogates and had outcome data were recruited for the presented analysis. This is a substudy of a complex evaluation of outcome of patients with asymptomatic higher degree valvular heart diseases. The complex study had been approved by the Ethics Committee of the Physician's Chamber of Berlin, and all patients gave written informed consent.

To assess the association between non-invasive surrogates and invasively measured LVEDP, we considered patients with eligible heart catheterization data and performed echocardiography as well as spiroergometry within 100 days of catheterization without intervening cardiac surgery or major change in symptom status. Catheterization was performed based on clinical indications. Due to the patient number that is necessary for multivariable analysis with surrogate parameters, their assessment was performed only in the entire VHD group. Prognostic value of filling pressure surrogates was investigated by a second cohort where follow-up data on valve surgery and mortality were available. Inclusion and exclusion criteria for the study were published previously [10]. In brief, patients in both cohorts we included asymptomatic moderate-severe VHD with an aortic valve area $<1 \mathrm{~cm}^{2}$ or a mean pressure gradient $>35 \mathrm{mmHg}$. Additionally patients were included with a volume overload by a more than second degree mitral or aortic regurgitation [11], evaluated by conventional tissue Doppler. All patients were in sinus rhythm with LVEF $\geq 50 \%$. Exclusion criteria were the following: severe coronary artery disease ( $>70 \%$ stenosis in a main coronary vessel), renal failure (creatinine $>180 \mu \mathrm{mol} / \mathrm{l})$, hepatic failure, severe pulmonary disease, anemia, malignant disease, and musculoskeletal disabilities that would potentially affect spiroergometric performance. A cut-off for LVEDP was set at $15 \mathrm{mmHg}$ to confirm the diagnosis of an elevated filling pressure. 


\subsection{Echocardiography}

Echocardiography was performed on a Vivid $5^{\circledR}$ ultrasound machine (GE Healthcare, Milwaukee, WI). Data were obtained from 2-D, M-mode, conventional, colour as well as tissue Doppler according to current guidelines [8]. Tissue doppler E', A' and S' were derived from the septal mitral-annular border. Aortic valve area and left ventricular mass were indexed per $\mathrm{m}^{2}$ of body surface area and ejection fraction by Simpson. For assessment of left ventricular filling pressure, we used the ratio of the transmitral pulse-wave Doppler early inflow E to the tissue Doppler E'-derived from the septal border of the mitral annulus (E/E'sep) as well as to the flow propagation velocity $(\mathrm{E} / \mathrm{Vp})$ measured by color M-mode. Moreover, the ratio of isovolumetric relaxation time to the difference between the time interval from the ECG-R-wave to the tissue Doppler E' and to the trans-mitral E (IVRT/TE'-TE) was used [12].

\subsection{Spiroergometry}

Each patient underwent a symptom-limited semi-supine cycle ergometer test with increasing work rate of 5 - 15 $\mathrm{W}$ per minute. A respiratory quotient of 1.1 was considered as indicating a sufficient exercise level. A 12-lead ECG was monitored continuously, and blood pressure and symptoms were assessed every 2 minutes. $\mathrm{O}_{2}$ consumption, $\mathrm{CO}_{2}$ production, and minute volume of ventilation (VE) were determined breath-by-breath by a gas analyzer (Quark PFT ${ }^{\circledR}$, Cosmed, Roma, Italy). At the maximum exercise stage, the highest 10 second average of $\mathrm{O}_{2}$ consumption values was taken to calculate the peak $\mathrm{O}_{2}$ consumption (peak $\mathrm{VO}_{2}$ ). $\mathrm{VO}_{2}$ was also assessed at the anaerobic threshold (AT) which was determined with preference of the V-slope in graph 5 of Wassermann-graphic. Ventilatory efficiency was expressed as the slope of ventilation versus $\mathrm{CO}_{2}$ output in graph 4 (VE/VCO ${ }_{2}$-slope) over the whole $\mathrm{VE} / \mathrm{VCO}_{2}$-curve [13]. Reduced exercise tolerance was defined as having a $\mathrm{VO}_{2}$ peak $<80 \%$ for given age and gender [14].

\subsection{Laboratory Analysis}

Blood was drawn from the cubital vein before the stress test. Samples were centrifuged, and stored at $-40^{\circ} \mathrm{C}$. Nterminal pro brain natriuretic peptide (NT-proBNP) was measured with the Elecsys-2010 ${ }^{\circledR}$ analyzer, Roche Diagnostics, Mannheim, Germany. As reported by the manufacturer, the limit of detection is $5 \mathrm{pg} / \mathrm{mL}$, and the cut-off for normal is $125 \mathrm{pg} / \mathrm{mL}$, in accordance with recommendations of the manufacturer (FDA-approved decision threshold for heart failure for patients age $<75$ years [15]. Laboratory personnel were blinded to clinical data.

\subsection{Invasive Measurements}

Catheterization was performed based on clinical indications. LVEDP was measured after proper insertion of a pigtail catheter into the left ventricle during breathhold at a near-end expiratory level by using a piezoelectric pressure transformer placed at the standardized level of $1 / 3$ the height of the thorax. Values from $3-5$ cardiac cycles were averaged, and systemic blood pressure was measured as well.

\subsection{Follow-Up}

Patients were followed for $694 \pm 576$ days. Death or valve surgery where registered during this follow-up period.

\subsection{Statistical Analyses}

We used SPSS version 13 for statistical analyses. Continuous variables are given as mean \pm SD. Categorical variables are given as percentage. For group differences, we applied the unpaired T-test for continuous variables and Chi-square-test in crosstabs for categorical variables. As NT-proBNP values were not normally distributed they were $\log 10$-transforrned for statistical calculations, respectively. Univariate analyses with LVEDP were performed with 37 parameters that significantly differed between the subgroup of patients with normal filling pressure and the subgroup with elevated filling pressure. For multivariable analysis we used two approaches: First, we constructed seven different models by adding to baseline characteristics and all our surrogates of elevated filling pressures alternatively either left ventricular EF, mass index, end diastolic diameter, left atrial di- 
mension, S'septal, IVRT/TÉ-TE or AP systolic measured during cath. Second, we constructed models for each surrogate separately where we added age, gender, S'sep, left ventricular mass index (LVMI) and end diastolic left atrial diameter (LAD), separately from each other diastolic as well as systolic measured arterial pressure (AP) during catheterization. The differences between AP measured during catheterization and measures during spiroergometry and echocardiography were assessed by a paired t-test. A Spearman's correlation was performed to assess the association between either LVEDP or its non-invasive correlates and AP measured at the same time. Kaplan-Meier curves were constructed for established surrogates of filling pressures as well as variables which were associated with LVEDP in our linear regression analysis: E/E’sep/lat, E/Vp, VE/ $\mathrm{VCO}_{2}$-slope, $\mathrm{VO}_{2} @ \mathrm{AT}$, peak $\mathrm{VO}_{2}$ and NT-proBNP. Receiver operating curves (ROC) were constructed for NT-proBNP to predict LVEDP in the first cohort and mortality or valve replacement in the second cohort. Optimal cut-off points and highest sum of sensitivity and specificity were identified in the ROC curves. A p-value $<0.05$ was considered significant.

\section{Results}

Left heart catheterization, echocardiography, and spiroergometry were all performed within 100 days in 54 patients without intervening cardiac surgery or major change in symptom status. These patients were included in cohort 1. Within this period, 7 out of 54 patients reported slight increase in symptoms into the mild range. All other patients' symptomatic status remained unchanged. Cohort 2, where follow-up data on valve surgery and mortality were available, consisted of 64 patients. Just 11 patients were included in both cohorts.

\subsection{Association between Invasively Measured LVEDP and Noninvasive Surrogates}

Patients in the first cohort with LVEDP > vs $\leq 15 \mathrm{mmHg}$ did not differ in their baseline characteristics Table 1. Echocardiographic and spiroergometric surrogates, blood pressure measured during heart catheterization, as well as NT-proBNP values of these patient groups are presented in Table 2.

Patients with elevated LVEDP showed lower $\mathrm{VO}_{2} \mathrm{AT}(\mathrm{p}<0.017)$, higher VE/ $/ \mathrm{VCO}_{2}$ slope $(\mathrm{p}<0.047)$, and higher NT-proBNP $(\mathrm{p}<0.048)$. $\mathrm{VO}_{2}$ peak values were lower-at a borderline significance level $(\mathrm{p}=0.058)$. All other parameters including echocardiographic surrogates of filling pressure did not differ between groups with and without elevated invasively measured LVEDP. In the univariate analysis of LVEDP as dependent variable with single 37 parameters, an association was found for S'sep $\left(\mathrm{R}^{2}=0.132, \mathrm{p}<0.008\right)$, VE/ $/ \mathrm{VCO}_{2}$ slope $\left(\mathrm{R}^{2}=\right.$ $0.120, \mathrm{p}<0.01)$, NT-proBNP $\left(\mathrm{R}^{2}=0.130, \mathrm{p}<0.01\right), \mathrm{VO}_{2} \mathrm{AT}\left(\mathrm{R}^{2}=0.095, \mathrm{p}<0.03\right)$, and A'mean $\left(\mathrm{R}^{2}=0.092, \mathrm{p}\right.$ $<0.04)$. In all those multivariable regression models, all potential surrogates for LVEDP were included together and mentioned covariables as well. $\mathrm{VO}_{2} \mathrm{AT}$ was an independent predictor of LVEDP ( $\mathrm{p}$-value at least of $<0.018$ ) also after adding diastolic AP measured during catheterization (p-value at least of $\mathrm{p}<0.019$ ). Adding systolic $\mathrm{AP}$ measured during catheterization, $\mathrm{VO}_{2} \mathrm{AT}$ remained as an independent predictor beside systolic AP as well (p-value at least of $<0.018$ ). Of note, during heart catheterization, a higher AP was measured than during spiroergometry as well as echocardiography $(141 \pm 23 / 69 \pm 11$ vs $133 \pm 16 / 78 \pm 10$ as well as $137 \pm 18 / 78 \pm 9 \mathrm{mmHg}$; $\mathrm{p}$ for systolic/diastolic pressure $<0.0001 / 0.004$ as well as $\mathrm{p}<0.06 / 0.17$, respectively). AP during heart catheterization correlated with AP before spiroergometry ( $\mathrm{p}<0.001$ for systolic and $\mathrm{p}<0.02$ for diastolic AP, respectively), but not with AP measured during echocardiography.

In multivariable analysis for each surrogate of LVEDP separately, once again only $\mathrm{VO}_{2} \mathrm{AT}$ was an independent predictor of LVEDP after correction by S'sep, LMVI and LAD (p-value at least $\mathrm{p}<0.049$ ). By adding AP during catheterisation as a covariable, systolic AP was an independent predictor as well $(\mathrm{p}<0.004)$.

\subsection{Surrogate Markers for LVEPD and Prognosis}

In the second cohort of 64 patients, follow-up investigation was completed after $694 \pm 576$ ( $\min 43$, max 2146) days. During follow-up, 3 cardiovascular deaths occurred and 41 patients received a valve replacement. Thus, 20 patients remained event-free.

For Kaplan-Meyer-curves of the noninvasive surrogate markers for LVEDP Figure 1(a) and Figure 1(b), NT-proBNP with a cut-off of $>125 \mathrm{pg} / \mathrm{ml}$ showed to be the only predictor for valve replacement or mortality ( $\mathrm{p}<$ 0.037). E/E'sep was of borderline significance for a worse prognosis $(p=0.054)$. In the subgroup of patients with aortic stenosis, $n=64$, Kaplan-Meyer-curves, Figure 2(a) and Figure 2(b), showed that both NT-proBNP 
and E/E'sep were predictive for our combined endpoint ( $\mathrm{p}<0.011$ and $<0.033$, respectively). The ROC curve analysis results are presented in Figure 3(a) and Figure 3(b). The best cutoff concentration of NT-proBNP to predict an elevated EDP, by our definition $>15 \mathrm{mmHg}$, was $421 \mathrm{pg} / \mathrm{mL}$ (sensitivity of $42 \%$ and specificity of $91 \%$ ). The best cut-off to predict our combined endpoint was identified at $122.45 \mathrm{pg} / \mathrm{ml}$ (sensitivity of $68 \%$ and specificity of $70 \%$ ), which is close to the recommended clinical upper limit of normal.

\section{Discussion}

We investigated patients with VHD and preserved ejection fraction and evaluated several non-invasive surrogates for left ventricular filling pressure including spiroegrometry, echocardiography, and laboratory biomarkers. Our results showed that $\mathrm{VO}_{2} \mathrm{AT}$ had the strongest association with invasively measured LVEDP. NT-proBNP was the strongest predictor of future valve surgery or death. Other commonly used non-invasive surrogates for left ventricular pressure were either just weakly or not at all associated with either LVEDP or prognosis.

In patients with VHD, especially those with preserved systolic function and who are asymptomatic, decision making for surgery is still challenging [16] [17]. Elevated LVEDP is one of the core parameters to characterize disease severity and by this might influence therapeutic decisions. Invasive measurement of this parameter is the

Table 1. Baseline clinical characteristics of both cohorts.

\begin{tabular}{|c|c|c|c|c|c|c|}
\hline \multirow[b]{2}{*}{ Characteristics } & \multicolumn{3}{|c|}{ 1) Cohort } & \multicolumn{3}{|c|}{ 2) Cohort } \\
\hline & $\begin{array}{l}\text { Entire } \\
\mathrm{n}=54\end{array}$ & $\begin{array}{c}\text { LVEDP }>15 \\
\mathrm{n}=28\end{array}$ & $\begin{array}{c}\text { LVEDP } \leq 15 \\
\mathrm{n}=26\end{array}$ & $\begin{array}{c}\text { p-Value } \\
\text { LVEDP }>15 \\
\text { vs }<15\end{array}$ & $\begin{array}{l}\text { Entire } \\
\mathrm{n}=64\end{array}$ & $\begin{array}{l}\text { AS only } \\
n=43\end{array}$ \\
\hline Age, y & $66 \pm 11.6$ & $67 \pm 11.8$ & $64 \pm 11.3$ & 0.163 & $63 \pm 13.8$ & $67 \pm 10.7$ \\
\hline Men, n (\%) & $34(63)$ & $16(57)$ & $18(69)$ & 0.408 & $43(68)$ & $28(65)$ \\
\hline BMI & $26 \pm 3.2$ & $26 \pm 3.3$ & $27 \pm 3$ & 1 & $27 \pm 3.4$ & $28 \pm 3.5$ \\
\hline EDD/BSA $\left(\mathrm{mm} / \mathrm{m}^{2}\right)$ & $28.3 \pm 4.4$ & $29 \pm 4.9$ & $28 \pm 3.9$ & 0.451 & $28 \pm 4.1$ & $26 \pm 3.5$ \\
\hline $\mathrm{ESD} / \mathrm{BSA}\left(\mathrm{mm} / \mathrm{m}^{2}\right)$ & $16.1 \pm 4.4$ & $16 \pm 4.9$ & $16 \pm 3.9$ & 0.844 & $15.1 \pm 4.1$ & $14 \pm 3.5$ \\
\hline $\mathrm{E}(\mathrm{cm} / \mathrm{sec})$ & $99 \pm 28$ & $97 \pm 29.6$ & $101 \pm 26.6$ & 0.553 & $101 \pm 30.5$ & $103 \pm 29$ \\
\hline $\mathrm{E} / \mathrm{A}$ & $1.14 \pm 0.45$ & $1.1 \pm 0.4$ & $1.2 \pm 0.5$ & 0.654 & $1.16 \pm 0.54$ & $1.12 \pm 0.59$ \\
\hline E-Deceleration time (msec) & $245 \pm 75$ & $247 \pm 79.5$ & $242 \pm 71.7$ & 0.812 & $230 \pm 66$ & $241 \pm 70.4$ \\
\hline \multicolumn{7}{|l|}{ Main diseases } \\
\hline Aortic stenosis, n (\%) & $33(61)$ & $17(61)$ & $16(62)$ & 1 & $43(67)$ & / \\
\hline Regurgitation vitium, n (\%) & $18(33)$ & $11(39)$ & $7(27)$ & 0.396 & $21(33)$ & l \\
\hline \multicolumn{7}{|l|}{ Concomittant Diseases } \\
\hline Hyperlipidemia, n (\%) & $13(24)$ & $5(18)$ & $8(31)$ & 0.346 & $27(42)$ & $21(49)$ \\
\hline Hypertension, n (\%) & $26(48)$ & $17(61)$ & $9(35)$ & 0.064 & $34(53)$ & $26(61)$ \\
\hline Diabetes mellitus, n (\%) & $8(15)$ & $5(18)$ & $3(12)$ & 0.706 & $9(14)$ & $7(16)$ \\
\hline Coronary Artery Disease, n (\%) & $17(32)$ & $8(29)$ & $9(35)$ & 0.771 & $11(17)$ & $9(21)$ \\
\hline COPD, n (\%) & $6(11)$ & $4(14)$ & $2(8)$ & 0.670 & $3(5)$ & $2(5)$ \\
\hline \multicolumn{7}{|l|}{ Drug Therapy } \\
\hline ACEI/ARB, n (\%) & $42(78)$ & $23(82)$ & $19(73)$ & 0.521 & $50(78)$ & $31(72)$ \\
\hline ß-Blockers, n (\%) & $29(54)$ & $16(57)$ & $13(50)$ & 0.785 & $28(44)$ & $17(40)$ \\
\hline
\end{tabular}

BMI, body mass index; COPD, chronic obstructive pulmonary disease; EDD, enddiastolic diameter; ESD, endsystolic diameter; E, early diastolic transmitral flow; E/A, ratio of early diastolic to late diastolic transmitral flow; ACEI, angiotensin-converting-enzyme-inhibitor; ARB, angiotensin II receptor antagonist. Values are given as mean \pm SD or as percent when appropiate. 
Table 2. Clinical Characteristics and surrogate markers of patients LVEDP > vs $\leq 15 \mathrm{mmHg}$.

\begin{tabular}{|c|c|c|c|}
\hline Characteristics & $\begin{array}{c}\text { LVEDP }>15 \\
n=28\end{array}$ & $\begin{array}{c}\text { LVEDP } \leq 15 \\
n=26\end{array}$ & p-Value \\
\hline \multicolumn{4}{|l|}{ Surrogate markers for filling pressure } \\
\hline E/E'septal & $16 \pm 6.3$ & $17 \pm 7.6$ & 0.967 \\
\hline $\mathrm{E} / \mathrm{Vp}$ & $2 \pm 0.9$ & $2 \pm 0.9$ & 0.693 \\
\hline IVRT/TE'-TE & $0.4 \pm 5.3$ & $0.004 \pm 6.3$ & 0.809 \\
\hline \multicolumn{4}{|l|}{ Cardiopulmonary function parameters } \\
\hline VE/VCO ${ }_{2}$ slope & $31 \pm 8.5$ & $28 \pm 4.6$ & 0.047 \\
\hline $\mathrm{VO}_{2}$ peak (ml/kg/min) & $19 \pm 6.1$ & $22 \pm 6.7$ & 0.058 \\
\hline $\mathrm{VO}_{2}$ Predicted (\%) & $81 \pm 26.8$ & $86 \pm 27.6$ & 0.499 \\
\hline $\mathrm{VO}_{2} \mathrm{AT}(\mathrm{ml} / \mathrm{kg} / \mathrm{min})$ & $12 \pm 3.3$ & $14 \pm 3.8$ & 0.017 \\
\hline Wattmax & $91 \pm 29.9$ & $110 \pm 46.1$ & 0.1 \\
\hline Heart rate at peak, bpm & $126 \pm 17.2$ & $122 \pm 24.5$ & 0.303 \\
\hline Syst AP, mmHg & $135 \pm 18.1$ & $130 \pm 11.3$ & 0.5 \\
\hline Syst AP at peak, mmHg & $179 \pm 20.9$ & $180 \pm 21.5$ & 0.683 \\
\hline Diast AP, mmHg & $78 \pm 10.6$ & $79 \pm 10.5$ & 0.626 \\
\hline Diast AP at peak, mmHg & $87 \pm 10.6$ & $88 \pm 10.8$ & 0.731 \\
\hline \multicolumn{4}{|l|}{ Biomarker } \\
\hline NT-proBNP (pg/mL) & $463 \pm 444.6$ & $245 \pm 267.2$ & 0.048 \\
\hline \multicolumn{4}{|l|}{ Echocardiographic parameters } \\
\hline LVMI/BSA (g/m²) & $142 \pm 36.7$ & $125 \pm 36$ & 0.101 \\
\hline $\mathrm{LAD} / \mathrm{BSA}\left(\mathrm{mm} / \mathrm{m}^{2}\right)$ & $25 \pm 2.9$ & $24 \pm 2.9$ & 0.114 \\
\hline EF (\%) & $62 \pm 7.8$ & $64 \pm 7.3$ & 0.369 \\
\hline S’septal (cm/sec) & $8 \pm 1.6$ & $9 \pm 2.8$ & 0.091 \\
\hline Flow propagation velocity $(\mathrm{cm} / \mathrm{sec})$ & $52 \pm 20.5$ & $50 \pm 14.5$ & 0.705 \\
\hline E’sep (cm/sec) & $6 \pm 1.9$ & $7 \pm 2.6$ & 0.389 \\
\hline A'sep (cm/sec) & $10 \pm 2.6$ & $11 \pm 2.6$ & 0.21 \\
\hline E’sep/A'sep & $0.7 \pm 0.3$ & $0.7 \pm 0.2$ & 0.655 \\
\hline E/E'lateral & $11 \pm 4.4$ & $13 \pm 6.1$ & 0.463 \\
\hline Syst AP (mmHg) & $138 \pm 18$ & $135 \pm 17$ & 0.421 \\
\hline Diast AP (mmHg) & $78 \pm 9$ & $78 \pm 9$ & 0.971 \\
\hline \multicolumn{4}{|l|}{ AP measured during heart catheterization } \\
\hline Syst AP (mmHg) & $152 \pm 52$ & $130 \pm 20$ & $<0.001$ \\
\hline Diast AP (mmHg) & $69 \pm 13$ & $70 \pm 10$ & 0.796 \\
\hline
\end{tabular}

A', E', late and early diastolic movement; AP syst, diast, arterial pressure systolic, diastolic; E/E', ratio of early transmitral inflow to E'; E'sep/A'sep, ratio of tissue Doppler early to late diastolic movement; EF, ejection fraction; E/Vp, ratio of transmitral to flow propagation; IVRT/TE'-TE, ratio of isovolumetric relaxation time to difference between times of R-wave to E' and to E; index; LAD, left atrial diameter; LVMI/BSA, left ventricular mass; S', tissue-Doppler systolic movement. Values are given as mean \pm SD. 


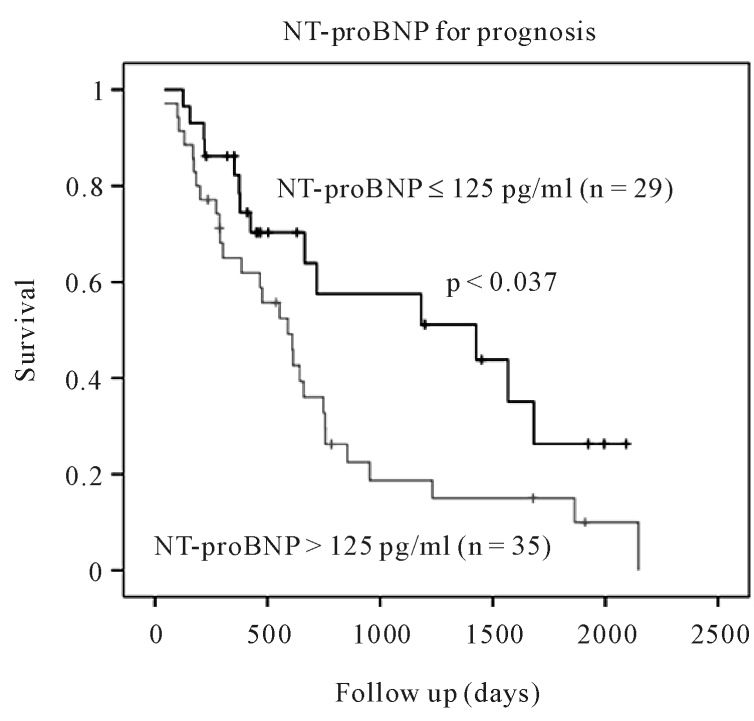

(a)

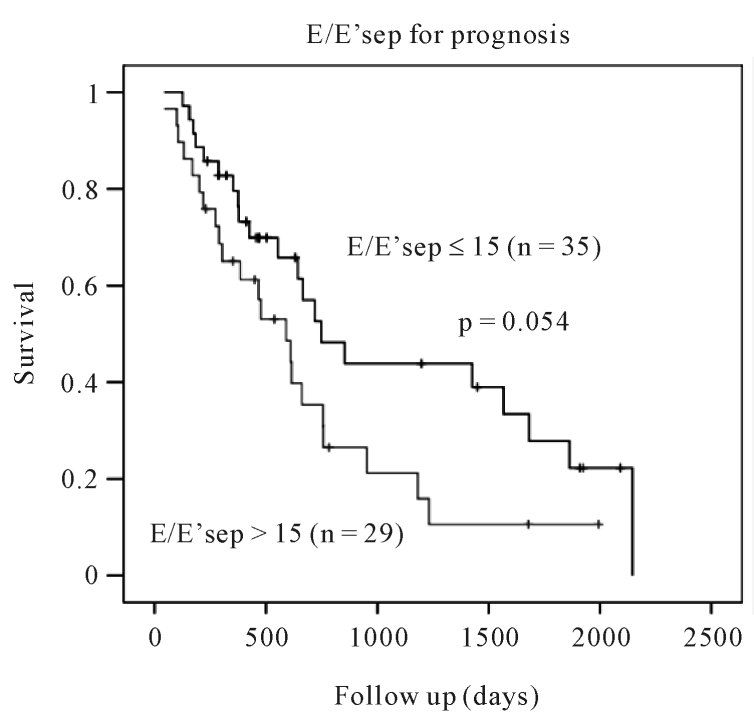

(b)

Figure 1. Prediction of mortality or valve replacement in the first cohort by (a) NT-proBNP per cutoff $\leq$ (black line)/>125 (grey line) $\mathrm{pg} / \mathrm{mL}$ as well as by (b) E/E'sep per cutoff $\leq$ (black line)/>15 (grey line). NT-proBNP performed significantly, $\mathrm{E} / \mathrm{E}$ 'sep was of borderline significance.

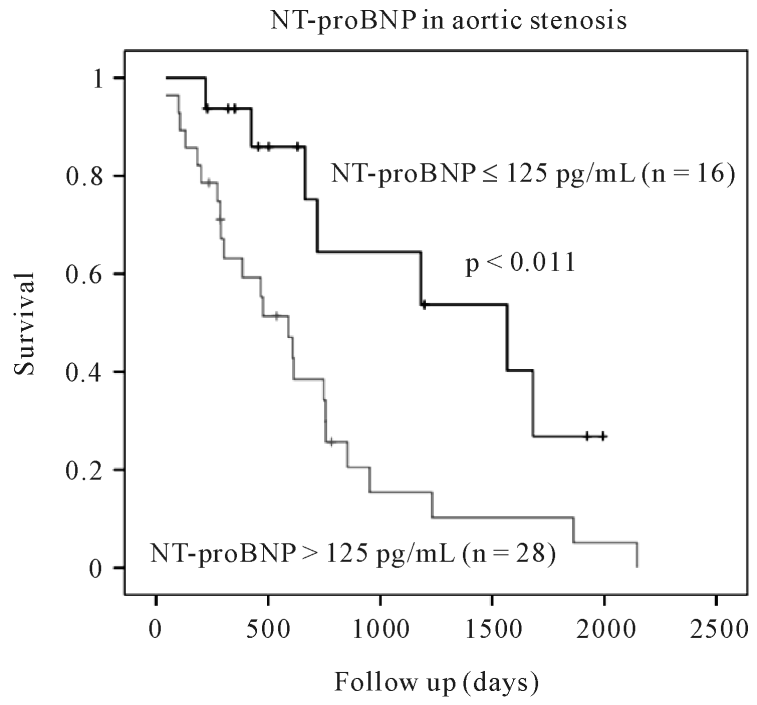

(a)

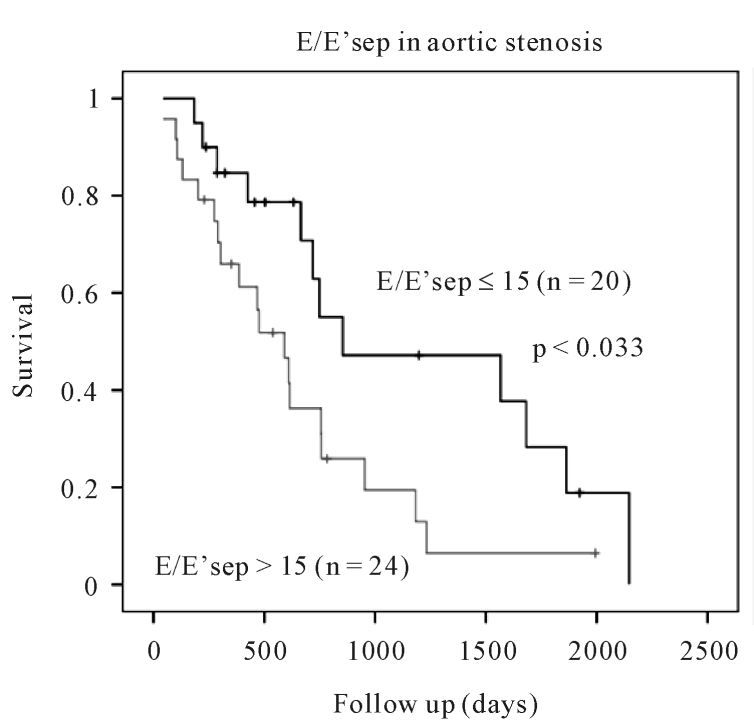

(b)

Figure 2. Prediction of mortality or valve replacement in the second cohort of aortic stenosis by (a) NT-proBNP per cutoff $\leq$ (black line)/>125 (grey line) $\mathrm{pg} / \mathrm{mL}$ as well as by (b) E/E'sep per cutoff $\leq$ (black line) $/>15$ (grey line). Both parameters perfomed significantly.

gold standard, but it is problematic for serial evaluations of asymptomatic patients due to safety, economic and time concerns. Therefore, valid non-invasive measures would be preferable.

In our first cohort, we found that $\mathrm{VO}_{2} \mathrm{AT}, \mathrm{VE} / \mathrm{VCO}_{2}$-slope, NT-proBNP and several echocardiographic measures such as $S^{\prime}$ and E/E'sep to be significantly associated with LVEDP. In our multivariable models, however, $\mathrm{VO}_{2} \mathrm{AT}$ was the only independent predictor of LVEDP. To our surprise, established echocardiografic surrogates for LVEDP were not predictive, though some previous studies have used parameters such as E/E' as a surrogate marker of elevated filling pressure [18]-[20].

Our data point out the necessity to define the validity of surrogate markers for filling pressure separately for different patient cohorts. For example, E/E' was associated with filling pressures in some studies [16] [18] but 


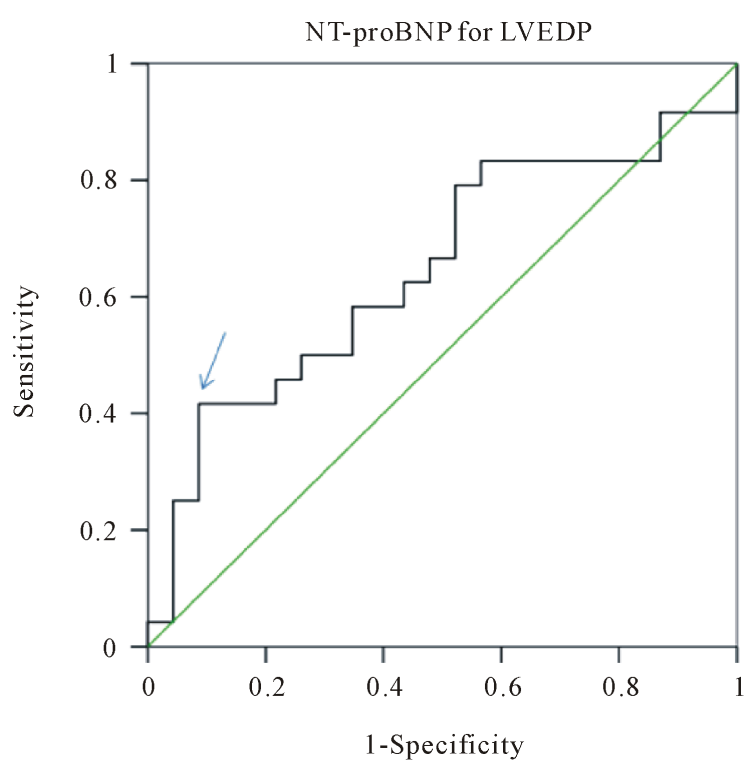

(a)

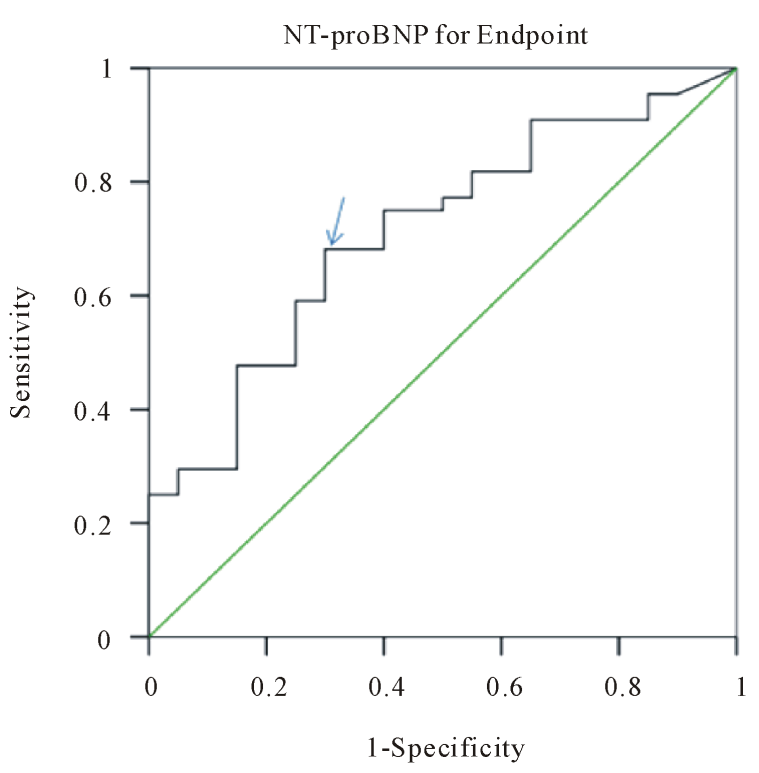

(b)

Figure 3. Best cut-off evaluation for NT-proBNP to (a) predict elevated LVEDP with a sensitivity of $42 \%$ and a specifitiy of $91 \%$ (arrow) and (b) to predict mortality or valve replacement with sensitivity of $68 \%$ and a specificity of $70 \%$ (arrow).

not in others [4] [5] [17]. For natriuretic peptides, it has also been observed in some cohorts that a significant correlation with hemodynamic parameters is lacking [21] [22]. Consequently, we suggest validation of surrogates for the management of specific types of cardiac disease separately.

In recent guidelines, IVRT/TE'-TE has also been introduced as a marker of filling pressure, especially for patients with small, hypertrophied ventricles [8]. However, data which confirm this relationship, to our knowledge, are sparse, though some data have been presented which show an association between filling pressure and the time difference TE'-TE [12] [23]. However, in our cohort, both TE'-TE and IVRT/TE'-TE failed to predict LVEDP.

Of note, no correlation between systolic AP measured during catheterization and during echocardiography was found in our cohort. This may partially explain the poor prediction of LVEDP by E/E' or E/Vp. Being dependent on afterload, LVEDP can vary during different settings or from day to day. This can be avoided by performing angiography and echocardiography simultaneously. In usual clinical practice, however, these tests are performed at different times. This caveat has to be considered when using E/E' as a surrogate of LVEDP.

Filling pressure is established as a major determinant of symptoms as well as of objective functional status of those patients, which is especially relevant for our asymptomatic patient group. Our results for $\mathrm{VO}_{2} \mathrm{AT}$ and, to a lesser extent, $\mathrm{VE} / \mathrm{VCO}_{2}$ slope confirmed this association. Since both these markers of objective exercise intolerance are prognostic in heart failure [24], they also might be useful for the management of asymptomatic VHD including the possibility of early indication for surgical treatment. These data are in line with previous results applying spiroergometry in asymptomatic VHD patients [10].

From all surrogate markers of elevated filling pressure tested, only NT-proBNP was able to predict outcomes. This is in accordance with several previous studies with natriuretic peptides [25] [26]. In the aortic stenosis sub group, E/E'sep was predictive as well. Previous studies by others showed a poor performance of E/E'sep in patients with mitral regurgitation [27] [28]. One might speculate that the poor correlation in patients with mitral regurgitation was responsible for the failed association with outcomes in our entire group of VHD since this parameter was predictive in our patients with aortic stenosis.

In summary, patients with moderate to severe asymptomatic VHD and preserved ejection fraction, NT-proBNP as well as $\mathrm{VO}_{2} \mathrm{AT}$ and $\mathrm{VE} / \mathrm{VCO}_{2}$ slope indicated elevated filling pressure as assessed invasively. The composite outcome of subsequent death or valve surgery was predicted by NT-proBNP, especially in patients with aortic stenosis. Echocardiographic parameters were of limited value for prognostic purposes in our study. Thus, noninvasive parameters reported to be surrogates for left ventricular filling pressure should be further investigated 
and then differentially used in patient groups with overloaded ventricles and preserved ejection fraction. Validated markers are warranted, particularly in patients with asymptomatic VHD, due to the challenging decisionmaking for surgery.

\section{Study Limitations}

First of all, this study is conducted on a small cohort, recruited from one center, and several types of VHD are included. The variety of investigated VHD has a different affection on the LVEDP. This may have a certain influence on the results. Further studies have to be performed including larger groups of single valvular diseases. Up to now, common filling pressure surrogates should be interpreted with caution.

Secondly, we accept a time interval up to 100 days between the invasive and non-invasive examinations. Though there is minimal change in symptomatic status during this time frame, a shorter time interval will have been preferable for research purposes. However, this time interval reflects routine patient management in a clinical setting. The vast majority of our outcomes are elective surgery $(n=41)$ rather than cardiac death $(n=3)$. Further studies employing larger cohorts with a single VHD type and with a shorter time interval between the examinations are required before routine use of spiroergometry and biomarkers for surgical decision-making are recommended.

\section{Acknowledgements}

Reagents for measuring NT-proBNP are kindly provided by Roche Diagnostics. There are no conflicts of interest for all authors.

\section{References}

[1] Halley, C.M., Houghtaling, P.L., Khalil, M.K., Thomas, J.D. and Jaber W.A. (2011) Mortality Rate in Patients with Diastolic Dysfunction and Normal Systolic Function. Archives of Internal Medicine, 171, 1082-1087. http://dx.doi.org/10.1001/archinternmed.2011.244

[2] Owan, T.E., Hodge, D.O., Herges, R.M., Jacobsen, S.J., Roger, V.L. and Redfield, M.M. (2006) Trends in Prevalence and Outcome of Heart Failure with Preserved Ejection Fraction. The New England Journal of Medicine, 355, 251-259. http://dx.doi.org/10.1056/NEJMoa052256

[3] Moller, J.E., Pellikka, P.A., Hillis, G.S. and Oh, J.K. (2006) Prognostic Importance of Diastolic Function and Filling Pressure in Patients with Acute Myocardial Infarction. Circulation, 114, 438-444. http://dx.doi.org/10.1161/CIRCULATIONAHA.105.601005

[4] Bhella, P.S., Pacini, E.L., Prasad, A., Hastings, J.L., Adams-Huet, B., Thomas, J.D., Grayburn, P.A. and Levine, B.D. (2011) Echocardiographic Indices Do Not Reliably Track Changes in Left-Sided Filling Pressure in Healthy Subjects or Patients with Heart Failure with Preserved Ejection Fraction. Circulation: Cardiovascular Imaging, 4, 482-489. http://dx.doi.org/10.1161/CIRCIMAGING.110.960575

[5] Mullens, W., Borowski, A.G., Curtin, R.J., Thomas, J.D. and Tang, W.H. (2009) Tissue Doppler Imaging in the Estimation of Intracardiac Filling Pressure in Decompensated Patients with Advanced Systolic Heart Failure. Circulation, 119, 62-70. http://dx.doi.org/10.1161/CIRCULATIONAHA.108.779223

[6] Maeder, M.T., Thompson, B.R., Brunner-La Rocca, H.P. and Kaye, D.M. (2010) Hemodynamic Basis of Exercise Limitation in Patients with Heart Failure and Normal Ejection Fraction. Journal of the American College of Cardiology, 56, 855-863. http://dx.doi.org/10.1016/j.jacc.2010.04.040

[7] Skaluba, S.J. and Litwin, S.E. (2004) Mechanisms of Exercise Intolerance: Insights from tissue Doppler Imaging. Circulation, 109, 972-977. http://dx.doi.org/10.1161/01.CIR.0000117405.74491.D2

[8] Nagueh, S.F., Appleton, C.P., Gillebert, T.C., Marino, P.N., Oh, J.K., Smiseth, O.A., Waggoner, A.D., Flachskampf, F.A., Pellikka, P.A. and Evangelisa, A. (2009) Recommendations for the Evaluation of Left Ventricular Diastolic Function by Echocardiography. European Heart Journal, 10, 165-193. http://dx.doi.org/10.1093/ejechocard/jep007

[9] Lancellotti, P., Magne, J., Donal, E., O’Connor, K., Dulgheru, R., Rosca, M. and Pierard, L.A. (2012) Determinants and Prognostic Significance of Exercise Pulmonary Hypertension in Asymptomatic Severe Aortic Stenosis. Circulation, 126, 851-859. http://dx.doi.org/10.1161/CIRCULATIONAHA.111.088427

[10] Schulz, O., Brala, D., Bensch, R., Krämer, J., Schulz-Menger, J., Berghoefer, G. and Schimke, I. (2012) Aortic Valve Replacement in Asymptomatic and Symptomatic Patients with Preserved Left Ventricular Ejection Fraction. The Journal of Heart Valve Disease, 21, 576-583.

[11] Zoghbi, W.A., Enriquez-Sarano, M., Foster, E., Graburn, P.A., Kraft, C.D., Levine, R.A., Nihoyannopoulos, P., Otto, 
C.M., Quinones, M.A., Rakowski, H., Stewart, W.J., Waggoner, A. and Weissman, N.J. (2003) Recommendations for Evaluation of the Severity of Native Valvular Regurgitation with Two-Dimensional and Doppler Echocardiography. Journal of the American Society of Echocardiography, 16, 777-802. http://dx.doi.org/10.1016/S0894-7317(03)00335-3

[12] Rivas-Gotz, C., Khoury, D.S., Manolios, M., Rao, L., Kopelen, H.A. and Nagueh, S.F. (2003) Time Interval between Onset of Mitral Inflow and Onset of Early Diastolic Velocity by Tissue Doppler: A Novel Index of Left Ventricular Relaxation: Experimental Studies and Clinical Application. Journal of the American College of Cardiology, 42, 14631470. http://dx.doi.org/10.1016/S0735-1097(03)01034-9

[13] Tabet, J.Y., Beauvais, F., Thabut, G., Tartiere, J.M., Logeart, D. and Cohen-Solal, A. (2003) A Critical Appraisal of the Prognostic Value of the $\mathrm{VE} / \mathrm{VCO}_{2}$ slope in Chronic Heart Failure. European Journal of Cardiovascular Prevention and Rehabilitation, 10, 267-272.

[14] Gulati, M., Black, H.R., Shaw, L.J., Arnsdorf, M.F., Merz, C.N., Lauer, M.S., Marwick, T.H., Pandey, D.K., Wicklund, R.H. and Thisted, R.A. (2005) The Prognostic Value of a Nomogram for Exercise Capacity in Women. New England Journal of Medicine, 353, 468-475. http://dx.doi.org/10.1056/NEJMoa044154

[15] Omland, T., Sabatine, M.S., Jablonski, K.A., Rice, M.M., Hsia, J., Wergeland, R., Landaas, S., Rouleau, J.L., Domanski, M.J., Hall, C., Pfeffer, M.A. and Braunwald, E. (2007) Prognostic Value of B-Type Natriuretic Peptides in Patients with Stable Coronary Artery Disease: The PEACE Trial. Journal of the American College of Cardiology, 50, 205-214. http://dx.doi.org/10.1016/j.jacc.2007.03.038

[16] Dini, F.L., Ballo, P., Badano, L., Barbier, P., Chella, P., Conti, U., De Tommasi, S.M., Galderisi, M., Ghio, S., Magagnini, E., Pieroni, A., Rossi, A., Rusconi, C. and Temporelli, P.L. (2010) Validation of an Echo-Doppler Decision Model to Predict Left Ventricular Filling Pressure in Patients with Heart Failure Independently of Ejection Fraction. European Heart Journal—Cardiovascular Imaging, 11, 703-710. http://dx.doi.org/10.1093/ejechocard/jeq047

[17] Firstenberg, M.S., Levine, B.D., Garcia, M.J., Greenberg, N.L., Cardon, L., Morehead, A.J., Zuckerman, J. and Thomas, J.D. (2000) Relationship of Echocardiographic Indices to Pulmonary Capillary Wedge Pressures in Healthy Volunteers. Journal of the American College of Cardiology, 36, 1664-1669. http://dx.doi.org/10.1016/S0735-1097(00)00909-8

[18] Ommen, S.R., Nishimura, R.A., Appleton, C.P., Miller, F.A., Oh, J.K., Redfield, M.M. and Tajik, A.J. (2000) Clinical Utility of Doppler Echocardiography and Tissue Doppler Imaging in the Estimation of Left Ventricular Filling Pressures: A Comparative Simultaneous Doppler-Catheterization Study. Circulation, 102, 1788-1794. http://dx.doi.org/10.1161/01.CIR.102.15.1788

[19] Hillis, G.S., Moller, J.E., Pellikka, P.A., Gersh, B.J., Wright, R.S., Ommen, S.R., Reeder, G.S. and Oh, J.K. (2004) Noninvasive Estimation of Left Ventricular Filling Pressure by E/E' Is a Powerful Predictor of Survival after Acute Myocardial Infarction. Journal of the American College of Cardiology, 43, 360-367. http://dx.doi.org/10.1016/j.jacc.2003.07.044

[20] Kasner, M., Westermann, D., Steendijk, P., Gaub, R., Wilkenshoff, U., Weitmann, K., Hoffmann, W., Poller, W., Schultheiss, H.P., Pauschinger, M. and Tschöpe, C. (2007) Utility of Doppler Echocardiography and Tissue Doppler Imaging in the Estimation of Diastolic Function in Heart Failure with Normal Ejection Fraction: A Comparative Doppler-Conductance Catheterization Study. Circulation, 116, 637-647. http://dx.doi.org/10.1161/CIRCULATIONAHA.106.661983

[21] Vasan, R.S. (2004) Expanding Indications for Natriuretic Peptides: Importance of Better New (Research) Protocols. American Heart Journal, 148, 743-746. http://dx.doi.org/10.1016/j.ahj.2004.04.044

[22] O’Neill, J.O., Bott-Silverman, C.E., McRae III, A.T., Troughton, R.W., Ng, K., Starling, R.C. and Young, J.B. (2005) B-Type Natriuretic Peptide Levels Are Not a Surrogate Marker for Invasive Hemodynamics during Management of Patients with Severe Heart Failure. American Heart Journal, 149, 363-369. http://dx.doi.org/10.1016/j.ahj.2004.05.051

[23] Min, P.K., Ha, J.W., Jung, J.H., Choi, E.Y., Choi, D., Rim, S.J., Jang, Y., Shim, W.H., Cho, S.Y. and Chung, N. (2007) Incremental Value of Measuring the Time Difference between Onset of Mitral Inflow and Onset of Early Diastolic Mitral Annulus Velocity for the Evaluation of Left Ventricular Diastolic Pressures in Patients with Normal Systolic Function and an Indeterminate E/E'. American Journal of Cardiology, 100, 326-330. http://dx.doi.org/10.1016/j.amjcard.2007.02.102

[24] Gitt, A.K., Wasserman, K., Kilkowski, C., Kleemann, T., Kilkowski, A., Bangert, M., Schneider, S., Schwarz, A. and Senges, J. (2002) Exercise Anaerobic Threshold and Ventilatory Efficiency Identify Heart Failure Patients for High Risk of Early Death. Circulation, 106, 3079-3084. http://dx.doi.org/10.1161/01.CIR.0000041428.99427.06

[25] Weber, M., Hausen, M., Arnold, R., Nef, H., Moellmann, H., Berkowitsch, A., Elsaesser, A., Brandt, R., Mitrovic, V. and Hamm, C. (2006) Prognostic Value of N-Terminal Pro-B-Type Natriuretic Peptide for Conservatively and Surgically Treated Patients with Aortic Valve Stenosis. Heart, 92, 1639-1644. http://dx.doi.org/10.1136/hrt.2005.085506

[26] Monin, J.L., Lancellotti, P., Monchi, M., Lim, P., Weiss, E., Piérard, L. and Gueret, P. (2009) Risk Score for Predicting Outcome in Patients with Asymptomatic Aortic Stenosis. Circulation, 120, 69-75. 
http://dx.doi.org/10.1161/CIRCULATIONAHA.108.808857

[27] Olson, J.J., Costa, S.P., Young, C.E. and Palac, R.T. (2006) Early Mitral Filling/Diastolic Mitral Annular Velocity Ratio Is Not a Reliable Predictor of Left Ventricular Filling Pressure in the Setting of Severe Mitral Regurgitation. Journal of the American Society of Echocardiography, 19, 83-87. http://dx.doi.org/10.1016/j.echo.2005.07.005

[28] Diwan, A., McCulloch, M., Lawrie, G.M., Reardon, M.J. and Nagueh, S.F. (2005) Doppler Estimation of Left Ventricular Filling Pressures in Patients with Mitral Valve Disease. Circulation, 111, 3281-3289.

http://dx.doi.org/10.1161/CIRCULATIONAHA.104.508812 